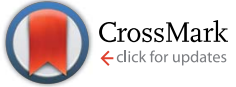

Cite this: RSC Adv., 2016, 6, 65299

Received 27th January 2016 Accepted 2nd June 2016

DOI: $10.1039 / c 6 r a 02476 a$

www.rsc.org/advances

\section{A comparison of catabolic pathways induced in primary macrophages by pristine single walled carbon nanotubes and pristine graphene}

\author{
Jennifer McIntyre, ${ }^{\text {*a }}$ Navin K. Verma, ${ }^{\mathrm{d}}$ Ronan J. Smith, ${ }^{\mathrm{c}}$ Caroline Moore, ${ }^{\mathrm{b}}$ \\ Hannah Nerl, ${ }^{\mathrm{c}}$ Niall McEvoy, ${ }^{c e}$ Nina Berner, ${ }^{c}$ Ignatius McGovern, ${ }^{f}$ Umar Khan, ${ }^{f}$ \\ Philip Lyons, ${ }^{c}$ Luke O'Neill, ${ }^{a}$ Valeria Nicolosi, ${ }^{c}$ Georg S. Duesberg, ${ }^{\text {ce }}$ Hugh J. Byrne, ${ }^{a}$ \\ Jonathan Coleman ${ }^{c}$ and Yuri Volkov ${ }^{\text {bc }}$
}

Understanding the correlation between the physico-chemical properties of carbonaceous nanomaterials and how these properties impact on cells and subcellular mechanisms is critical to their risk assessment and safe translation into newly engineered devices. Here the toxicity, uptake and catabolic response of primary human macrophages to pristine graphene (PG) and pristine single walled carbon nanotubes (pSWCNT) are explored, compared and contrasted. The nanomaterial toxicity was assessed using three complementary techniques (live-dead assay, real time impedance technique and confocal microscopic analysis), all of which indicated no signs of acute cytotoxicity in response to PG or pSWCNT. Transmission electron microscopy (TEM) demonstrated that PG was phagocytosed by the cells into single membrane lysosomal vesicles, whereas the primary macrophages exposed to pSWCNT contained many double membrane vesicles indicative of an autophagic response. These distinct catabolic pathways were further verified by biochemical and microscopic techniques. Raman spectroscopic mapping was used to explore the nanomaterial uptake and distribution. Based on the G-band, significant uptake and accumulation of the PG in discrete vesicles was recorded, whereas the PSWCNT were not taken up to the same extent. Thermogravimetric analysis (TGA) of the cells treated with PG revealed that $\sim 20-30 \%$ of the remaining dry mass was made up of PG. No detectable amount of pSWCNT was recorded using TGA. TEM analysis confirmed that PG was still graphitic even after 24 hours of accumulation in the lysosomal compartments. In conclusion, these two nanomaterials, with similar surface chemistries but unique geometries, differ significantly in their uptake mechanisms and subsequently induced lysosomal and autophagic catabolic pathways in human primary macrophages.

\section{Introduction}

The emergence of a myriad of forms of engineered nanoparticles and their potential applications in a range of technologies, from composites to nanomedicine has led to concerns regarding their potential detrimental impact on human health and the environment. This is particularly the case for carbonaceous nanomaterials, such as fullerenes, single walled carbon nanotubes (SWCNTs), graphene and their

\footnotetext{
${ }^{a}$ FOCAS Research Institute, Dublin Institute of Technology, Kevin Street, Ireland. E-mail: jennifer.mcintyre@dit.ie

${ }^{b}$ School of Medicine, Trinity College Dublin, Ireland

${ }^{c}$ Centre for Research on Adaptive Nanostructures \& Nanodevices (CRANN), Advanced Materials and BioEngineering Research (AMBER) Centre, Trinity College Dublin, Ireland

${ }^{d}$ Lee Kong Chian School of Medicine, Nanyang Technological University, Singapore ${ }^{e}$ School of Chemistry, Trinity College Dublin, Ireland

${ }^{f}$ School of Physics, Trinity College Dublin, Ireland
}

derivatives, as the conjugated $\pi$-electron densities which give rise to their specific functional characteristics also render their surfaces particularly chemically active. The inevitable surge in large-scale synthesis and use of such carbonaceous nanomaterials implies that, from a manufacturing, application and disposal perspective, there is a broad range of biological exposure routes that could be potentially hazardous, and thus it is of paramount importance to assess their potential risks. The Organisation for Economic Co-operation and Development (OECD) recognises graphene and single walled carbon nanotubes as nanomaterials that require appropriate safety assessment at the different levels of a biological organisation, where negative health effects such as cellular responses or adverse molecular interactions can occur, with an ultimate focus on the reduction and replacement of animal testing (OECD). ${ }^{1}$ Since the first reports on the potential hazards of nanomaterials and the emergence of the field of nanotoxicology, however, it has become clear that a more systematic approach to nanomaterial screening is required, and, in particular, the importance of 
relating biological responses and their underlying mechanisms to the physico-chemical properties of the nanomaterials has become apparent. ${ }^{2-4}$

In this study, the in vitro response of human primary macrophages following exposure to pristine single walled carbon nanotubes (pSWCNT) and pristine graphene (PG) is examined. Notably, these two types of nanomaterials have similar surface chemistries, but feature very different shapes, and thus their cellular uptake and intracellular response mechanisms can be compared and contrasted. Primary macrophages are employed as the model in vitro test system, as they represent one of the first lines of defence against foreign invaders in the human body, and, using a combination of advanced microscopic, spectroscopic and biochemical techniques the toxicity, uptake, ultimate location and degradation of these two nanomaterials following exposure to phagocytic cells is explored. It is demonstrated that the two carbonaceous nanomaterials with similar surface chemistries but distinct geometries differ significantly in their uptake mechanisms and subsequent induced catabolic pathways.

\section{Results}

\section{Nanomaterial characterisation}

Correct interpretation of the bio-nano interactions can only be achieved when the physico-chemical properties of the nanomaterial in question are fully understood. Using a number of imaging and spectroscopic techniques, the PG and pSWCNT used in this study were characterised in detail. The graphene and SWCNT, along with the exfoliation methods, used here have been characterised extensively previously. ${ }^{5-8}$ Representative scanning electron microscopy images of the pSWCNT and PG flakes cast onto silicon are shown in Fig. 1A and B. The pSWCNT samples were predominantly of dimension $\sim 500 \mathrm{~nm}$ and the PG contained flakes of mean length $\sim 500 \mathrm{~nm}$. These measurements were supported by dynamic light scattering (DLS) measurements. Although this technique is not recommended for non-spherical samples, it does confirm a normal distribution of samples size for both graphene (Fig. 1E) and the nanotubes (Fig. 1F). Representative Raman spectra of the PG and pSWCNT are shown in Fig. 1G, along with a photograph of the PG and pSWCNT suspensions. In Raman spectroscopy of graphitic materials, the intensity of the $\mathrm{D}$ band relative to the $\mathrm{G}$ band can be used to indicate the defect content in a sample. ${ }^{9}$ Importantly, the relative intensity of the $\mathrm{D}$ band shown in Fig. $1 \mathrm{G}$ is significantly larger than that of the graphite starting material. Previously, it has been shown that an increase in the relative intensity of the $\mathrm{D}$ band with respect to the starting material for liquid phase exfoliated samples is consistent with the creation of edges, as flakes are cut during sonication..$^{\mathbf{1 0 - 1 2}}$ It is also important to note that the change in the $2 \mathrm{D}$ band for graphene films compared to the bulk graphite is indicative of exfoliation. ${ }^{13}$ X-ray photoelectron carbon 1 s core level spectra were measured on relatively thick vacuum deposited PG and pSWCNT films, as shown in Fig. 1C and D Both the flakes and the nanotubes show a dominant $\mathrm{sp}^{2}$ carbon component, as is expected for high quality samples, and show similar relative
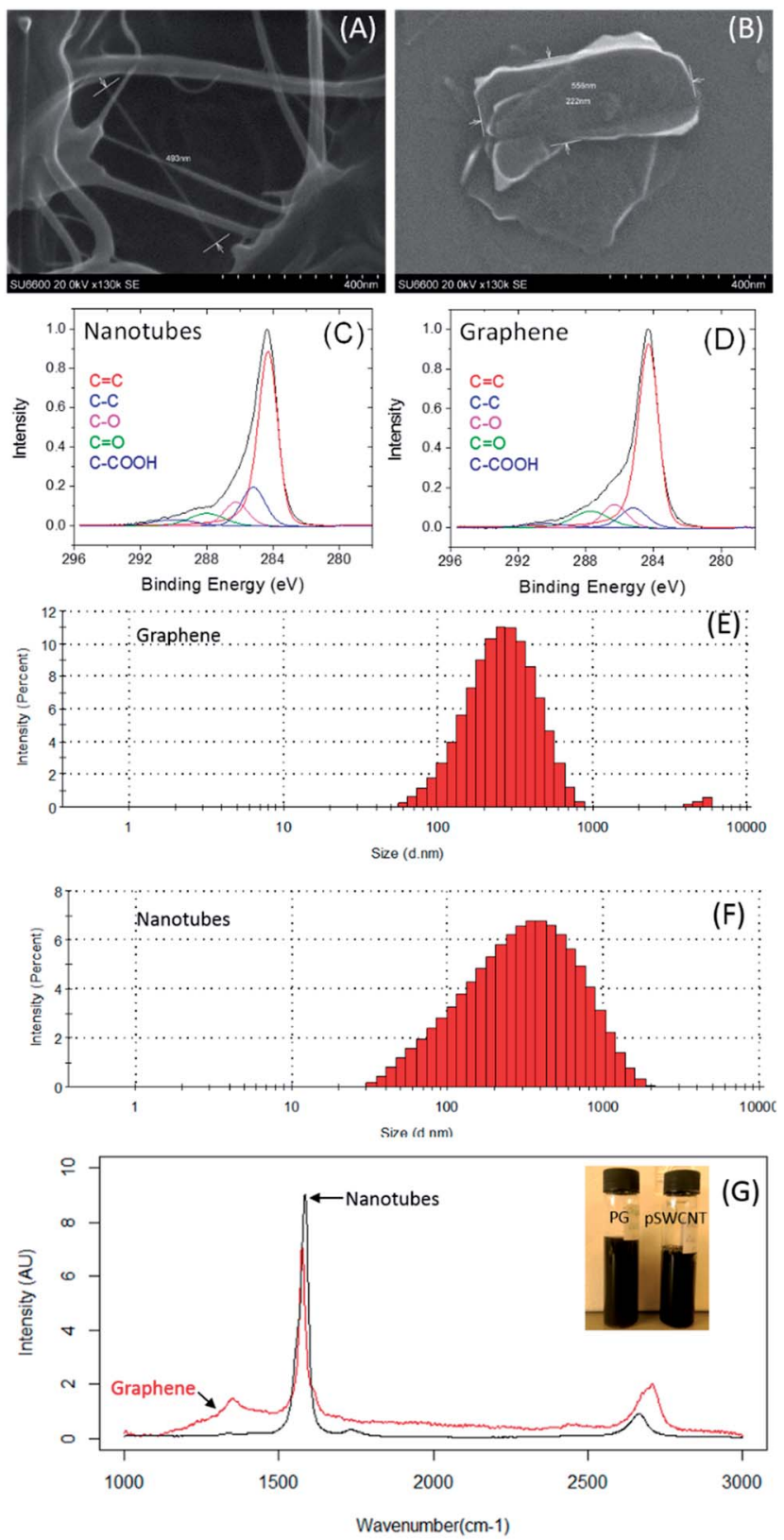

Fig. 1 Physico-chemical characterisation of PG and pSWCNT. Representative SEM images of PSWCNTs and PG flakes deposited on silicon ( $A$ and $B$ ) both with an average size of $\sim 500 \mathrm{~nm}$, supported by dynamic light scattering illustrating a normal distribution of sample size ( $\mathrm{E}$ and $\mathrm{F}$ ). X-ray photoelectron spectroscopy was used to explore the presence of oxidation defects of both pSWCNT (C) and PG (D). Average Raman spectra illustrating characteristic D, G, and 2D bands around 1350, 1580 and $2700 \mathrm{~cm}^{-1}$ respectively (G). The photo inset in (G) shows the PG and PSWCNT dispersions.

amounts of the different oxide species $(\mathrm{C}-\mathrm{O}, \mathrm{C}=\mathrm{O}$ and $\mathrm{COOH})$, as shown in Table 1, at higher binding energy values indicating that the two samples are chemically very similar. The presence of these oxides is consistent with previous results obtained for liquid phase exfoliated graphene and is due to residual surfactant (containing these oxide species) adsorbed to the surface of the films. ${ }^{14}$ The most pronounced difference lies in 
Table 1 XPS relative content of different oxide species populations (\%) for the graphene (PG) and nanotubes (pSWCNT)

XPS - species populations (\%)

\begin{tabular}{llllll}
\hline & $\mathrm{C}=\mathrm{C}$ & $\mathrm{C}-\mathrm{C}$ & $\mathrm{C}-\mathrm{O}$ & $\mathrm{C}=\mathrm{O}$ & $\mathrm{C}-\mathrm{COOH}$ \\
\hline PG & 65 & 10 & 10 & 12 & 3 \\
pSWCNT & 60 & 17 & 11 & 8 & 4 \\
\hline
\end{tabular}

the intensity of the $\mathrm{sp}^{3}$ carbon component at a binding energy of $285.2 \mathrm{eV}$. This difference is most likely due to different levels of residual surfactant. Graphene and nanotubes predominantly contain $\mathrm{sp}^{2}$ bonded carbon atoms, whereas the surfactants are entirely composed of $\mathrm{sp}^{3}$ bonded carbon atoms. A greater amount of residual surfactant on the tubes would hence increase the $\mathrm{sp}^{3}$ contribution. This is plausible since the surfactant to tube ratio is much greater than the surfactant to graphene ratio in dispersion. Raman spectroscopy and XPS confirmed that the exfoliated graphene flakes used throughout this study are un-oxidised and feature very low defect density.

\section{Cytotoxicity assessment}

Acute toxicity of the PG and pSWCNT suspensions in the primary macrophages was explored using different approaches, a live-dead assay and a whole cell-based electrical impedance sensing technique. For the live-dead assay, the primary macrophages were exposed to PG and pSWCNT and their respective surfactants, sodium cholate (SC) and sodium dodecyl sulfate (SDS) (at a series of dilutions in complete media $(0,0.1$, $1,2,5,10 \mu \mathrm{g} \mathrm{ml}{ }^{-1} ; 200 \mu \mathrm{l}$ per well) for 24 hours). Fig. 2 represents the results for cells following the treatment with the

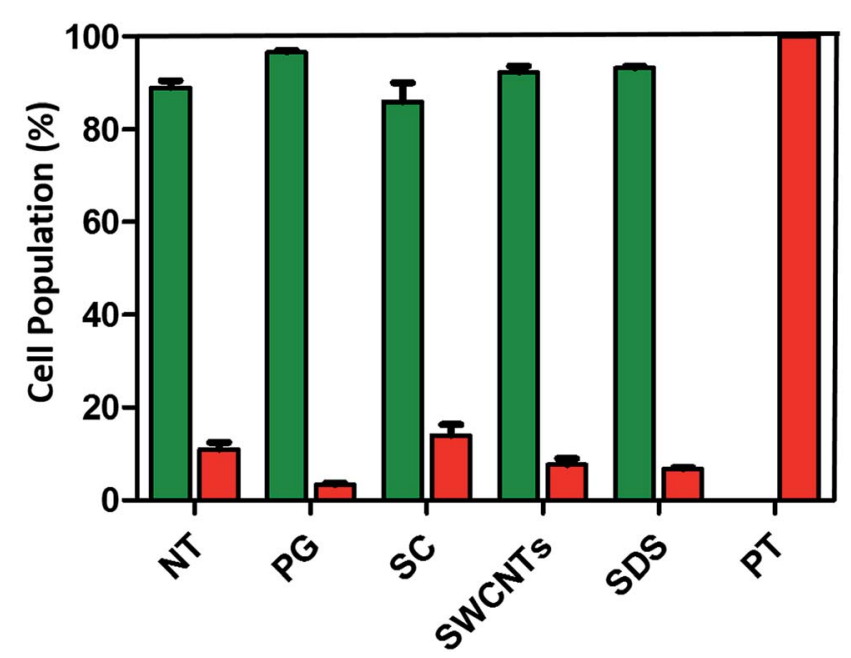

Fig. 2 Live-dead assay where the primary macrophages were exposed to PG, and pSWCNT and their respective surfactants, sodium cholate (SC) and sodium dodecyl sulfate (SDS). The graph represents the results for the cells following the treatment with nanomaterials at the highest concentration of $10 \mu \mathrm{g} \mathrm{ml}^{-1}$. Neither of the carbonaceous nanomaterials or surfactants induced a significant increase in cell death compared to the untreated control, indicative of a non-toxic response. highest nanomaterial concentration of $10 \mu \mathrm{g} \mathrm{ml} l^{-1}$. The average cell viability is determined by the ratio of dead to live cells. $100 \%$ cell death was observed following treatment with $70 \%$ methanol (positive control, PT). Interestingly, none of the carbonaceous nanomaterials or surfactants induced a significant increase in cell death compared to the untreated control, which is indicative of a non-toxic response. For the real-time electrical impedance technique (RTI) the primary cells were allowed to differentiate from monocytes to macrophages on the electrodes for a period of $168 \mathrm{~h}$, following which they were treated with $1 \mu \mathrm{g} \mathrm{ml}^{-1}$ of PG or pSWCNT and monitored in realtime for a further $96 \mathrm{~h}$. An increase in impedance, which is plotted as cell-index, is caused by the adherence of cells to the bottom surface of the wells. The untreated cells reached maximum impedance at around $216 \mathrm{~h}$ and remained at the same level until the end of the experiment (Fig. 3). Nocodazole treatment (which interferes with the polymerization of microtubules and thus cell adherence to the bottom of the plate) results in cell death leading to a decrease in cell index, gradually reaching baseline levels due to the loss of cell adhesion. The cells exposed to the PG or pSWCNT followed a trend similar to the untreated cells, with a maximum cell index at $216 \mathrm{~h}$ and no subsequent significant drop, thus indicating that neither nanomaterial had a detectable effect on cell adhesion. These data fully correlate with the findings presented above that neither the PG nor pSWCNT induce an acute toxic effect in the primary macrophages.

Confocal microscopy was used to study the cellular morphology of the primary macrophages following exposure to the PG and PSWCNT via two different scenarios (i.e. cells either grown on thin films containing PG or pSWCNT and cells exposed to PG or pSWCNT suspensions). Cell adhesion characteristics, cytoskeletal and nuclear morphologies were explored. The primary macrophages were grown on glass coverslips, PG thin films, or pSWCNT thin films for 10 days (Fig. 4a, d, b and c respectively). Another set of primary macrophages was exposed to PG or pSWCNT suspensions (Fig. 4c and d respectively). Using cytoskeletal stains for F-actin, tubulin and a nuclear stain, these cells were imaged and

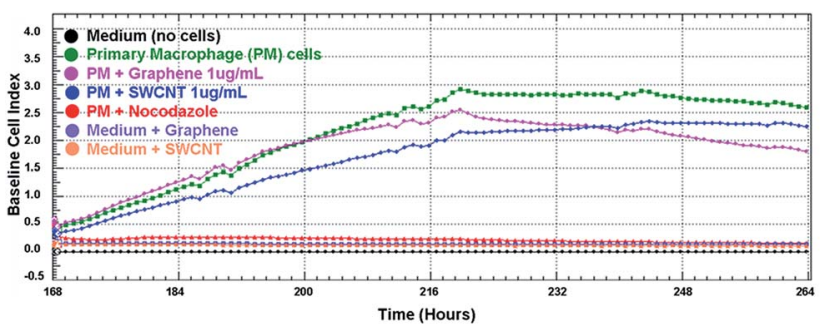

Fig. 3 Detection of primary macrophage cell adhesion by real time impedance measurement over 11 days. Following attachment of the cells to the bottom of the well they partially insulate the electrodes which causes a rise in impedance (cell index). After 7 days (168 h) monocytes differentiated into macrophages and adhered to the bottom of the plate. The untreated cells and those treated with PG or pSWCNT showed no significant difference in cell index over $96 \mathrm{~h}$, indicating the fully preserved cell adhesion and confirming the absence of toxic effect from either nanomaterial. 

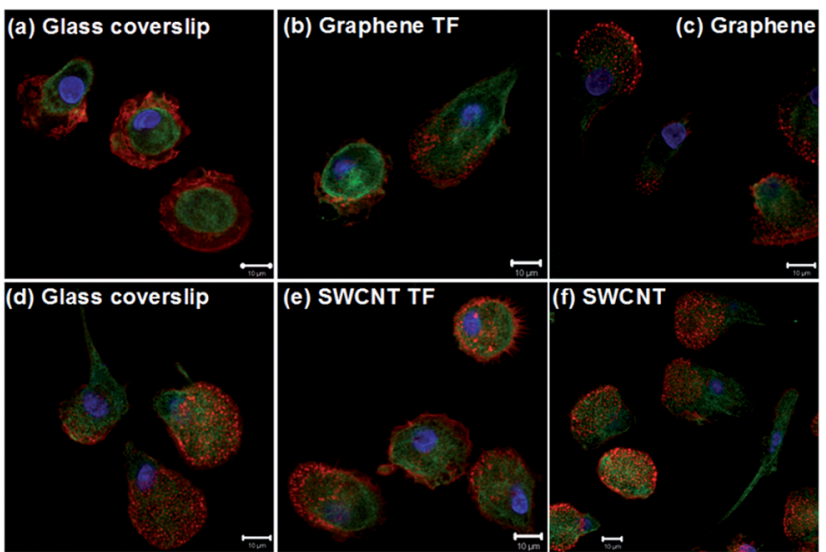

Fig. 4 Confocal microscopy images of primary macrophages stained for actin (red), tubulin (green) and nucleus (blue), grown on glass coverslips ( $a$ and d), graphene thin films (b), pSWCNT thin film (e), exposed to PG (c) or pSWCNT suspensions. All of the cells displayed normal morphology and showed no signs of acute toxicity when grown on the thin films or exposed to the nanomaterial suspensions.

analysed by confocal microscopy. The cells grown on the glass coverslips displayed normal cytoskeletal and nuclear morphologies. The cells grown on the PG or SWCNT thin films also presented with consistent normal morphology (Fig. $4 \mathrm{~b}$ and $\mathrm{e}$ respectively), with no signs of necrosis (loss of membrane integrity, swelling of cytoplasm or cell lysis) or apoptosis (membrane blebbing, shrinking of cytoplasm, condensation of nucleus or fragmentation of cell into smaller bodies). Following exposure to PG or pSWCNT suspensions, macrophages displayed normal cytoskeletal and nuclear morphologies with no signs of acute toxicity (Fig. 4c and $2 d$, respectively). These confocal images of the cells following treatment with the nanomaterial suspensions are in concert with the results from the live-dead assays and the RTI experiments.

\section{Nanomaterial uptake and catabolic responses}

Transmission electron microscopy (TEM) revealed the formation of filipodia in response to both the PG and pSWCNT

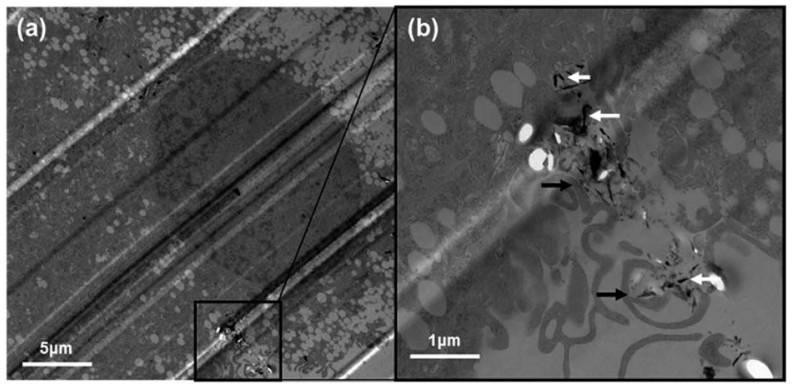

Fig. 5 TEM images of a representative primary macrophage following $4 \mathrm{~h}$ exposure to PG. The uptake of the graphene by phagocytosis can be clearly seen with the formation of filopodia (black arrows) around the graphene (white arrows). These images confirm that phagocytosis is the uptake mechanism of the PG into the cells. Note: the diagonal grooves represent the unavoidable artefacts in the process of cutting cells containing hard carbonaceous nanomaterials. however, there is only evidence of uptake of the PG by the primary macrophages enabled by this phagocytic mechanism. At $4 \mathrm{~h}$ post treatment, the formation of filipodia around the PG is evident (the filopodia are indicated by black arrows and the PG is indicated by white arrows in Fig. 5). Although the cells treated with the pSWCNT similarly showed the formation of filipodia in response to the nanomaterial, there was no evidence of phagocytosis of the pSWCNT. TEM images taken $24 \mathrm{~h}$ post treatment show that the PG was taken up in abundance by the primary macrophages and is ultimately located within single membrane vesicles (Fig. 6a-c). The PG is present in densely packed multi-layered aggregates within these single membrane lysosomal vesicles. This phagocytic pathway of uptake is not surprising for nanomaterials in the $500 \mathrm{~nm}$ range and has been well documented previously. ${ }^{15}$ The presence of the large single membrane lysosomal vesicles was not observed in cells treated with the SWCNT. The most striking subcellular features observed in the primary macrophages following treatment with pSWCNT was the formation of multiple double membrane vesicles which are characteristic of autophagic vesicles (Fig. 6d-f). All of these autophagic vesicles were very dense and contrasted to the rest of the subcellular regions. However, as it was not possible to confirm whether or not they contained pSWCNT using TEM imaging, further experiments using Raman spectroscopy and TGA were used to further explore this. It should be noted that no such double membrane vesicles containing similar dense regions were observed in the control cells or in those treated with PG. These TEM data clearly suggest, firstly that the graphene is phagocytosed by the primary macrophages and, secondly that two distinct catabolic pathways are induced in response to the PSWCNT and PG, an autophagic and lysosomal pathway, respectively.

Confocal microscopy was used to explore further the autophagic and lysosomal response of the cells to the pSWCNT and

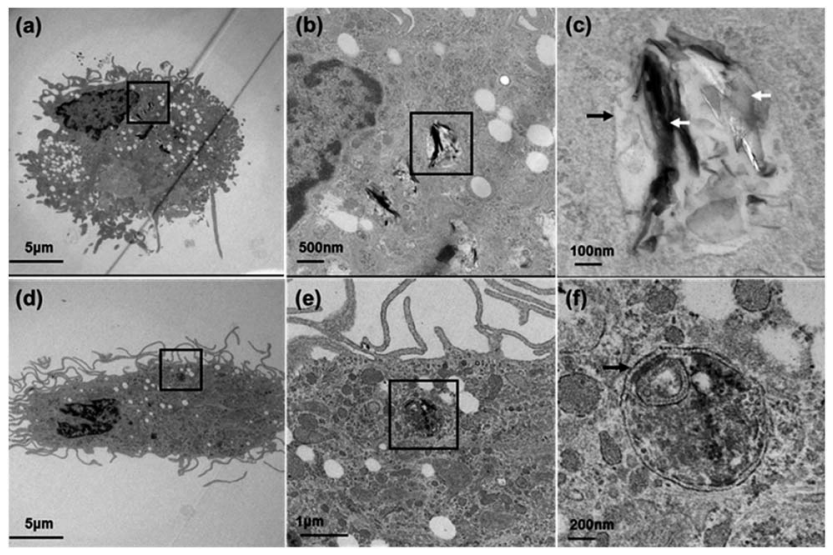

Fig. 6 Representative transmission electron microscopy images of whole primary macrophages following $24 \mathrm{~h}$ exposure to $1 \mu \mathrm{g} \mathrm{ml}^{-1}$ of PG (a) or pSWCNT (d). The higher magnification TEM images (b) reveal PG (c, white arrows) are located within a single membrane lysosomal vesicles (c, black arrow). The pSWCNT induce an autophagic response in the primary macrophages, which is reflected in the fact that many double-membrane autophagic vesicles with electron-dense content appear in these cells (e), and in higher magnification ( $f$, black arrow) whereas the PG does not. 
PG. Firstly, LAMP proteins were stained, which are the most abundant constituents of lysosomal membranes. In untreated cells, the LAMP protein staining has a diffuse cytoplasmic distribution (Fig. 7a). In contrast, following the treatment with the PG, LAMP proteins are now arranged in a pattern of large vesicles, indicative of the formation of lysosomes (Fig. 7c). The lysosomes formed following the treatment with SWCNT were considerably smaller in size and not as abundant (Fig. 7d). These images are consistent with the type of subcellular vesicles observed using TEM.

The cells were also stained for microtubule-associated protein light chain 3 (LC3) which is located on the inner and outer membranes of the double membrane autophagic vesicles. LC3 modification is essential for the formation of autophagosomes. The lipidated form LC3-II of the cytosolic LC3-I is a definitive marker of autophagy induction in mammalian cells. ${ }^{16}$ In untreated cells, the LC3-II was predominantly distributed diffusely throughout the cell, apart from the presence of a couple of larger puncta (Fig. 8a). The presence of these larger puncta is not unusual, as the autophagic process is a homeostatic process and occurs at a basal level in all cells enabling the degradation of old proteins and organelles. Chloroquine was used as a positive control as it is arrests autophagy ${ }^{\mathbf{1 7}}$ causing a build-up of autophagic vesicles, and therefore the accumulation of LC3-II protein in the cells (Fig. 8b). Following a $24 \mathrm{~h}$ exposure to PG, the LC3-II is distributed diffusely throughout the cells (Fig. 8c), similarly to
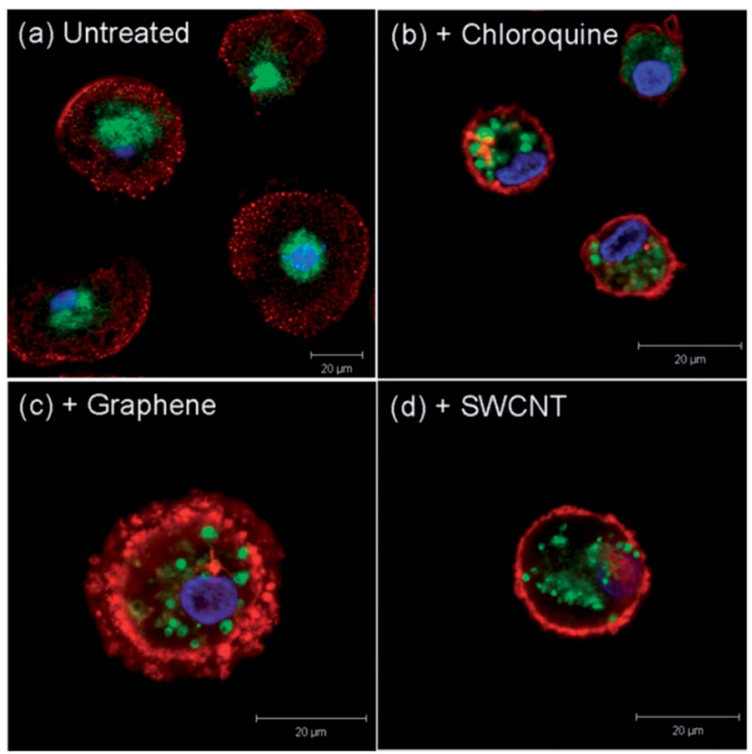

Fig. 7 Lysosomal response of cells explored by confocal microscopy. Primary macrophages were stained for the lysosomal marker LAMP protein (green), actin (red), and nucleus (blue). Each image represents a $0.9 \mu \mathrm{m}$ optical slice through a cell. Control untreated cells (a), cells treated with chloroquine for $4 \mathrm{~h}$ (b), $1 \mu \mathrm{g} \mathrm{ml}^{-1}$ PG (c) or SWCNT (d) for $24 \mathrm{~h}$. Compared to the untreated cell (a), where the LAMP staining has a diffuse distribution throughout the cytoplasm, there is a marked increase in the formation of lysosomes following treatment with the PG (c) which are significantly larger than those formed following pSWCNT treatment (d). These observations are consistent with the TEM findings.
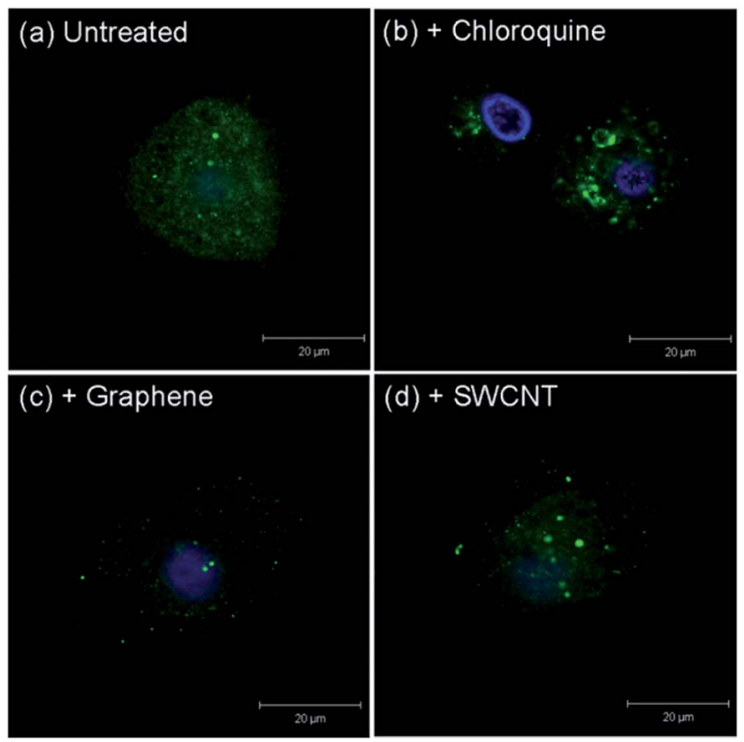

Fig. 8 Autophagic response of primary macrophages investigated by confocal microscopy. Cells were stained for the autophagic marker LC3-II protein (green) and nuclei (blue). Cells were treated with $1 \mu \mathrm{g}$ $\mathrm{ml}^{-1} \mathrm{PG}$ (c), or pSWCNT (d) for $24 \mathrm{~h}$, and chloroquine (b) for $4 \mathrm{~h}$ as a positive control for autophagy. The LC3-II was predominantly distributed diffusely throughout the untreated cells, apart from the presence of a few larger puncta (a) and a similar pattern was observed in the cells treated with PG (c). Cells treated with pSWCNT typically showed an increase in the presence of large puncta (d).

the pattern also observed in the untreated cells. This dramatically contrasts with a marked increase in the size and distribution of autophagic vesicles in the cells treated with pSWCNT (Fig. 8d). This observed size difference in autophagic vesicles

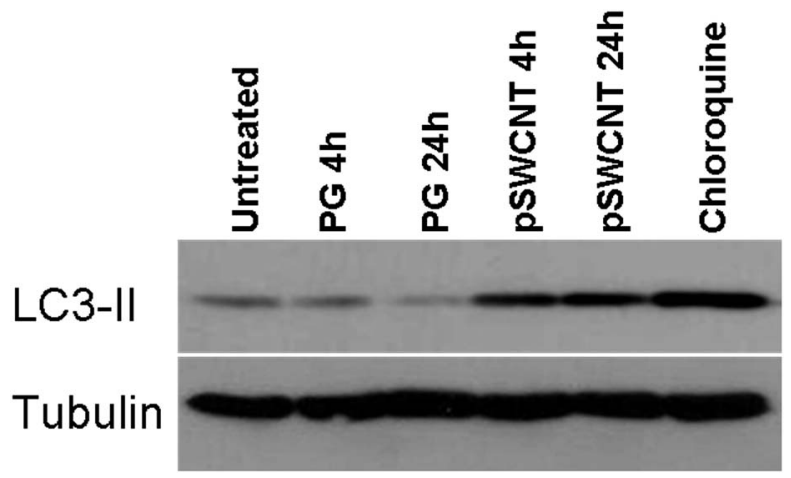

Fig. 9 Western blot analysis of the autophagy marker LC3 protein induction in primary human macrophages. Cells were treated with or without $1 \mu \mathrm{g} \mathrm{ml}^{-1}$ of PG or pSWCNT for 4 or $24 \mathrm{~h}$, or with chloroquine for $2 \mathrm{~h}$ as a positive control for autophagy. Cell lysates were separated by SDS-PAGE, transferred to PVDF membrane, and probed with antiLC3 or anti- $\alpha$-tubulin antibodies. The amount of LC3-II protein expressed in the cells treated with pristine graphene is on par with the control cells, which indicates the presence of a basal level of autophagic activity. However, the expression of LC3-II protein following pSWCNT is significantly higher than in the control and this increased expression confirms an autophagic response to the PSWCNT, which is in consistency with the TEM imaging and confocal microscopy observations. 
and distribution was further investigated and quantified by SDS-PAGE and western immunoblotting. Following up to $24 \mathrm{~h}$ incubation with PG, the macrophages showed the LC3-II levels comparable with untreated cells, indicative of the absence of autophagic response (Fig. 9). Strikingly, pSWCNT treated cells showed a marked increase in the amount of LC3-II protein, which remained elevated even after $24 \mathrm{~h}$ (Fig. 9), clearly indicating the induction of autophagy.

\section{Quantification of nanomaterial uptake}

The TEM images confirmed that PG was taken up in abundance by the cells, but the level to which the pSWCNT were endocytosed remained unclear using this technique. Raman spectroscopy and thermogravimetric analysis were therefore employed to address this. Raman spectroscopic mapping was carried out using a $20 \times$ dry objective which gave a spot size of $\sim 1.6 \mu \mathrm{m}$ enabling a large volume of cell to be measured and analysed. Both PG and pSWCNT have a discrete Raman peak at $\sim 1580 \mathrm{~cm}^{-1}$ which is known as the G-band. The presence of this $\mathrm{G}$ band in a Raman spectrum would confirm the presence of PG or pSWCNT within the cells and therefore Raman maps generated based on the G-band sum were acquired along with an accompanying brightfield image. Fig. 10a and b illustrate a typical Raman map and brightfield image of primary macrophages following exposure to the PG. Raman mapping revealed the presence of PG throughout the entire cell, compared to little or no uptake of the pSWCNT (Fig. 10b and d, respectively). The

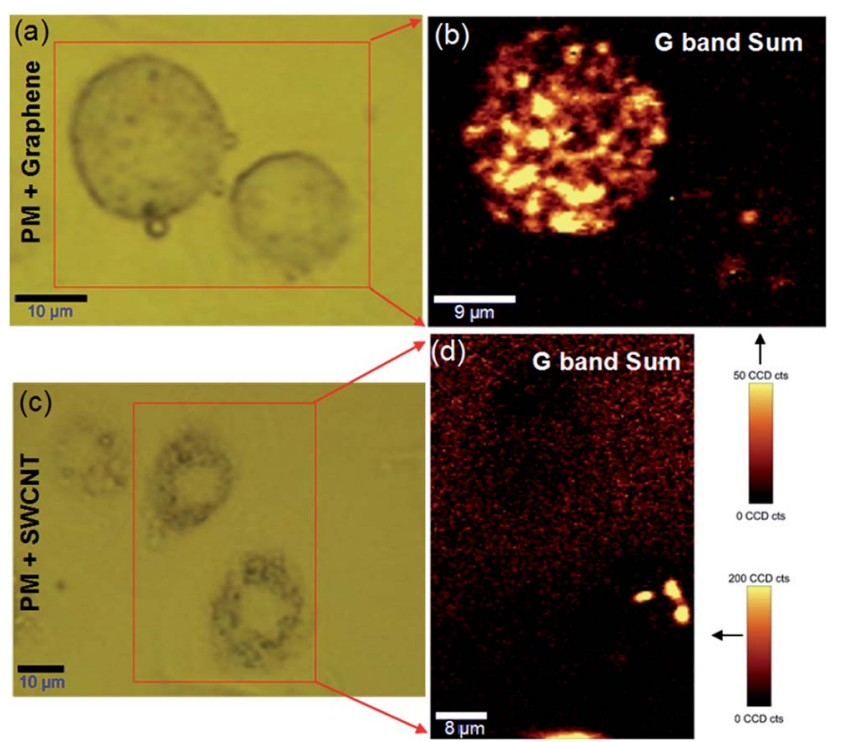

Fig. 10 Raman mapping of primary macrophages. Brightfield images of cells following $24 \mathrm{~h}$ treatment with $1 \mu \mathrm{g} \mathrm{ml}^{-1}$ of PG (a) or pSWCNT (c) with corresponding Raman maps (b) and (d). The Raman maps are generated based on the $G$ band $\sim 1580 \mathrm{~cm}^{-1}$ which is present in the spectra of both PG and PSWCNT, indicates their localisation within the cells and does not overlap with any cell-attributed peaks. The PG is present in abundance within the primary macrophages as evidenced in (b) and is arranged in a vesicular pattern similar to that observed for lysosomal staining. The pSWCNT are taken up in significantly lower quantity (d).
PG appeared to be located in discrete regions of the cell in a vesicular pattern, consistent with the observed increase in lysosomal vesicles by fluorescent microscopy and single membrane vesicles packed with PG imaged by TEM. In contrast, following pSWCNT exposure, little or no uptake was observed by Raman spectroscopy compared to the amount of PG taken up by the cells. To quantify the amount of nanomaterial uptake, TGA analysis was carried out. It was found that approximately $20-30 \%$ of the remaining dry mass of the cells treated with PG was made up of PG whereas the amount of pSWCNT in the cells was below the detection limits of the system (Fig. 11). These data confirm that the PG was taken up in abundance by the cells whereas the pSWCNT displayed a dramatically lower level of endocytosis.

\section{Analysis of biodegradation of pristine graphene}

Finally, HRTEM analysis was carried out to explore the integrity of the pristine graphene within the cells after $24 \mathrm{~h}$. Fig. 12 shows two examples of the typical PG lattice structures measured from within the cells at the 4 - and $24 \mathrm{~h}$ time-points. The presence of the lattice fringes shows that the graphitic structure remained intact. The inset in Fig. 12 shows the line profiles taken across the transect $\mathrm{A}-\mathrm{B}$, measuring the periodic distance between the lattice fringes. The spacing between the lattice fringes of the structures was found to be approximately $0.34 \mathrm{~nm}$ for both time points, $4 \mathrm{~h}$ and $24 \mathrm{~h}$, which is what is expected for pristine graphene. In addition, the second inset shows the fast Fourier transform (FFT) of the TEM image. This further confirmed the presence of crystalline material in the region. It can be concluded from this data that the PG remains graphitic and

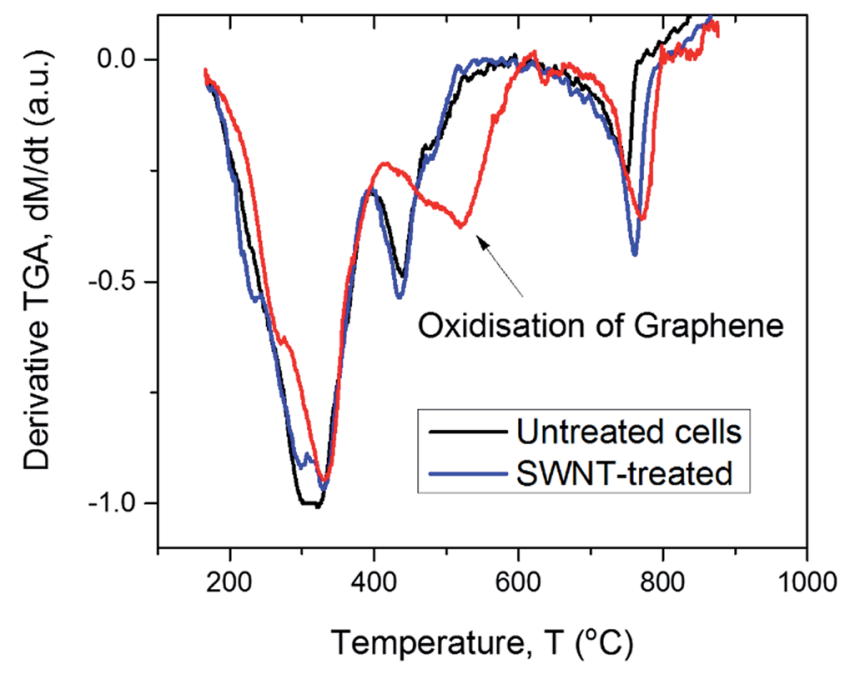

Fig. 11 Thermogravimetric plot of reduced region $\left(200-900^{\circ} \mathrm{C}\right.$ ) where the PG and pSWCNT oxidisation can be observed. The plot represents untreated cells and cells following treatment with PG or pSWCNT. The plots obtained from the untreated cell and cells following pSWCNT treatment are nearly identical and the pSWCNT amount is evidently below the detection limits of this technique. The uptake of PG within the cells is confirmed by the graphene oxidisation (black arrow) and is estimated to make up $20-30 \%$ of the total remaining dry mass. 


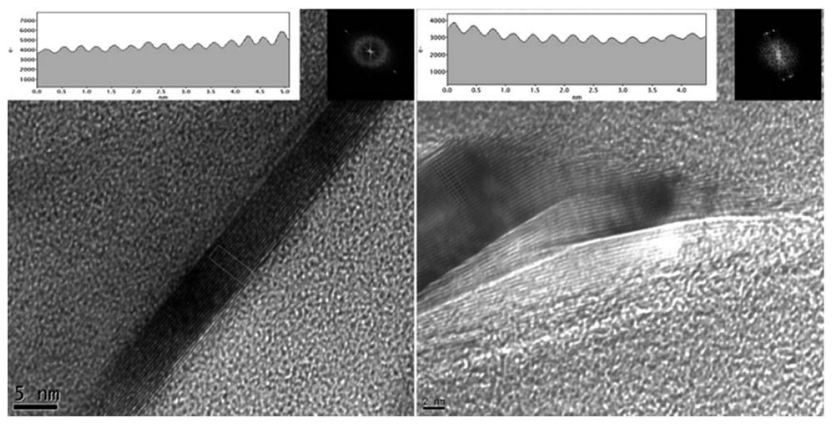

Fig. 12 HRTEM images of typical graphene lattice structures measured in the cells following $4 \mathrm{~h} \mathrm{(a)}$ and $24 \mathrm{~h}$ (b) accumulation in single membrane vesicles. The spacing between the lattice fringes of the structures was found to be approximately $0.34 \mathrm{~nm}$ for both time points, which is what can be expected for unchanged intact PG.

does not undergo detectable degradation even after $24 \mathrm{~h}$ accumulation within the lysosomal compartments of primary macrophages.

\section{Experimental}

\section{Cell culture and treatments}

Peripheral blood mononuclear cells (PBMCs) were isolated from the buffy coat of anonymous healthy donors (provided with permission by the Irish Blood Transfusion Service) by centrifugation on Lymphoprep (Axis-Shield, Oslo, Norway) density gradient, washed and re-suspended in RPMI-1640 culture medium, supplemented with $10 \%$ pooled human serum type $\mathrm{AB}$ (Sigma), with $100 \mathrm{mg}$ of penicillin per $\mathrm{mL}$ and $100 \mathrm{mg}$ of streptomycin per mL (Sigma, P4333). Cells were seeded at a density of $5 \times 10^{6}$ cells per ml onto glass coverslips that were placed in 24 well tissue-culture plates (Fisher Scientific Ireland Ltd., Dublin, Ireland). Non-adherent cells were removed by washing with warm medium every 2-3 days. MDMs were cultured for 7 days before treatment (apart from those that were seeded onto the thin films from day 1).

Immortalised bone marrow-derived macrophages (iBMM) from C57BL/6 mice stably expressing EGFP-LC3 (GFP-LC3) described previously (Harris et al., 2011; Hartman and Kornfeld, 2011) and cultured in Gibco® RPMI 1640 medium were used. In all cases the medium was supplemented with $10 \%(\mathrm{v} / \mathrm{v})$ fetal bovine serum, $50 \mathrm{U} \mathrm{ml}^{-1}$ penicillin and $50 \mu \mathrm{g} \mathrm{ml}^{-1}$ streptomycin, and cells were cultured in a humidified incubator at $37{ }^{\circ} \mathrm{C}$ and $5 \% \mathrm{CO}_{2}$. iBMM cells were maintained in $5 \mu \mathrm{g} \mathrm{ml} \mathrm{m}^{-1}$ puromycin. All cell culture reagents were obtained from Life Technologies Corporation (Bio-Sciences, Dublin, Ireland). Cells were seeded onto round cover slips in 24 well tissue-culture plates (Fisher Scientific Ireland Ltd., Dublin, Ireland) at a density of $5 \times 10^{3}$ cells per well.

\section{Graphene/SWCNT dispersions and thin films}

The pristine graphene (PG) dispersions (TCD) used in this work were prepared by adding $2500 \mathrm{mg}$ of graphite powder, purchased from Sigma-Aldrich (product number 332461) to
$100 \mathrm{ml}$ of aqueous surfactant solution $\left(0.5 \mathrm{mg} \mathrm{ml}^{-1}\right.$ sodium cholate) to give an initial graphitic concentration of $25 \mathrm{mg} \mathrm{ml}^{-1}$. This mixture was sonicated using a sonic tip (a Sonics VX-750 ultrasonic processor with a flat head tip) for $60 \mathrm{~min}$ at $75 \%$ of the maximum power (i.e. $75 \%$ of $750 \mathrm{~W}$ nominal maximum power). The dispersion was left to stand overnight. The top $50 \mathrm{ml}$ was decanted into a $28.5 \mathrm{ml}$ vials and centrifuged (HettichMikro 22R) for $90 \mathrm{~min}$ at $1500 \mathrm{rpm}$. The top $15 \mathrm{ml}$ in each vial was then decanted. UV-Vis-IR absorption spectroscopy (Varian Cary 6000i) was carried out immediately after centrifugation. The concentration of graphene remaining dispersed after centrifugation was calculated from the absorption spectra using an extinction coefficient of $6600 \mathrm{ml}^{-1} \mathrm{~g}^{-1} \cdot{ }^{18}$

Single walled carbon nanotube (Iljin Nanotech) dispersions were prepared in a similar manner by adding nanotubes to a solution of sodium dodecyl sulphate surfactant in water (5 $\mathrm{mg} \mathrm{ml}^{-1} \mathrm{SDS}$ ) such that the nanotube concentration was $1 \mathrm{mg} \mathrm{m}{ }^{-1}$. This dispersion was subjected to $5 \mathrm{~min}$ of high power tip sonication (VibraCell CVX; $750 \mathrm{~W}, 20 \% 60 \mathrm{kHz}$ ), then placed in a sonic bath for $1 \mathrm{~h}$, and then subjected to another 5 min of high-power sonication. The resulting dispersion was left to stand overnight before being centrifuged (HettichMikro 22R) for $90 \mathrm{~min}$ at $5500 \mathrm{rpm}$.

Individual dispersions of PG and pSWCNT were sonicated in water surfactant solutions as described previously. Following centrifugation of these samples to remove any un-exfoliated material, the dispersed concentration was accurately determined by UV-Vis-nIR absorption spectroscopy. A predetermined concentration of PG or pSWCNT was filtered onto nitrocellulose membrane by vacuum filtration and washed with 11 of deionised water to remove excess surfactant. After washing, the film was allowed to dry at room temperature in a vacuum oven.

\section{Scanning electron microscopy}

Suspensions of the PG and pSWCNT were prepared at a concentration of $0.007 \mathrm{mg} \mathrm{ml}^{-1}, 20 \mu \mathrm{l}$ of the suspension was pipetted onto silicon and allowed to dry. A Hitachi SU6600 was used to record the SEM images. Both the PG and pSWCNT were imaged using an accelerating voltage of $20 \mathrm{kV}$ and a magnification of $\times 130 \mathrm{k}$.

\section{Dynamic light scattering}

Suspensions of the PG and pSWCNT were prepared at a concentration of $0.026 \mathrm{mg} \mathrm{ml}^{-1} .1 \mathrm{ml}$ of this suspension was added to cuvette and size measurements were carried out using a Malvern Zetasiser Nano Series Nano ZS system.

\section{Cell staining}

Peripheral blood mononuclear cells (PBMCs) were seeded at a density of $1 \times 10^{6}$ cells per $\mathrm{ml}$ on the two types of thin films or in 8 well Labtek chamber slides (Nunc, Thermo Fisher). After 10 days the cells were fixed with $4 \%$ paraformaldehyde for 30 minutes at room temperature, washed once with PBS and permeabilised with $0.1 \%$ Triton-X for $3 \mathrm{~min}$. Cells were washed twice with PBS and stained. Nuclei were stained with Hoechst 33342 (Sigma), 1:1000 dilution, secondary anti-body alexa 
$488 \mathrm{~nm}$ (Molecular Probes) (1: 1000 dilution), and actin stained with rhodamine phalloidin (Invitrogen) (1:250 dilution) was added for 60 minutes. Two more final washes with PBS and a cover slip was then mounted on the thin films using mounting media (DAKO) and left to dry overnight before imaging.

Lysosomal staining. Cells were fixed with $4 \%$ paraformaldehyde for $30 \mathrm{~min}$ at room temperature, washed once with PBS and permeabilised with $0.1 \%$ Triton-X for $3 \mathrm{~min}$. Lamp primary antibody (Lamp-1, H5G11) was added for 2 h. Cells were washed twice with PBS and the stained for nuclei (Hoechst 33342, Sigma), actin (anti- $\alpha$-actin, Sigma) and Alexa $488 \mathrm{~nm}$ secondary for $1 \mathrm{~h}$. Two more washes were done before the coverslips with cells growing on them were inverted, mounted onto glass slides and left to dry overnight at ambient temperature before imaging.

Autophagosomal staining. Cells were fixed in methanol for 6 min at $-80^{\circ} \mathrm{C}$, washed once with PBS and permeabilised with 0.1\% Triton-X for $3 \mathrm{~min}$. Anti-LC3 (N-Terminal, Clone2G6 (nanotools)) was added for $2 \mathrm{~h}$. Cells were washed twice with PBS and the stained for nuclei (Hoeschst) and alexa $488 \mathrm{~nm}$ secondary for $1 \mathrm{~h}$. The coverslips were further processed and mounted as described above for lysosomal staining.

\section{Confocal and fluorescent microscopy}

Confocal imaging was carried out using a laser scanning Zeiss LSM510-Meta microscope (Carl Zeiss Microimaging Inc., NY, USA) with a $\times 63$ oil immersion objective lens. Excitation wavelengths used were $405 \mathrm{~nm}, 488 \mathrm{~nm}$ and $561 \mathrm{~nm}$ and emission filters were BP 420-480 nm, BP 505-530 nm and $572-754 \mathrm{~nm}$ respectively.

\section{Impedance measurements}

Real-time monitoring of electrical impedance (which depends on cell number, degree of adhesion, spreading, and proliferation of the cells) to determine cytotoxic effects of graphene or single walled carbon nanotubes was performed using an xCELLigance system as per manufacturer's instructions (Roche Applied Science, West Sussex, UK). Briefly, cells were seeded at a density of $10 \times 10^{6}$ cells per ml into $200 \mu \mathrm{l}$ of media in the E-Plate $($ ) (cross interdigitated micro-electrodes integrated on the bottom of 96-well tissue culture plates by micro-electronic sensor technology) and left to attach onto the electrode surface for 7 days, allowing monocytes to differentiate into macrophages. The electrical impedance was recorded every hour. At $168 \mathrm{~h}$ time point the cells were treated with graphene or SWCNT in triplicates and monitored for an additional $96 \mathrm{~h}$. The cell impedance, expressed in the arbitrary units of 'Cell Index', was automatically calculated by the xCELLigence system and converted into growth curves (a protocol which has been previously optimized and reported $\left.{ }^{18-20}\right)$.

\section{Cell viability screening using the CytellTM}

Peripheral blood mononuclear cells (PBMCs) were seeded at a density of $1 \times 10^{6}$ cells per ml $\left(2 \times 10^{5}\right.$ cells per well; $200 \mu \mathrm{l}$ per well) in a 96-well Nunc plates in RPMI media (Gibco, Life Technologies, cat no. 61870) supplemented with $10 \%$ human serum type $\mathrm{AB}$ male (Sigma, H4522) and 1\% Penicillin-Streptomycin (Sigma, P4333). Cells were incubated for 3 days at $37{ }^{\circ} \mathrm{C}, 5 \% \mathrm{CO}_{2}$ to allow the start of cell differentiation into macrophages, washed with warm culture medium and incubated over further 4 days until monocyte/macrophage differentiation has been completed. Primary macrophages were exposed to pristine graphene (PG) or single walled carbon nanotubes (SWCNTs) and nanomaterial surfactants at a series of dilutions in complete media $\left(0,0.1,1,2,5,10 \mu \mathrm{g} \mathrm{ml}^{-1} ; 200 \mu \mathrm{l}\right.$ per well) for $24 \mathrm{~h}$. Untreated cells (negative control) and cells exposed to $70 \%$ methanol for $30 \mathrm{~min}$ (positive control) were also included in the experimental design. After $24 \mathrm{~h}$, cells were washed and stained using CytellTM Cell Viability Kit (GE Healthcare, Life Sciences). A $4 \times$ reagent master mix (50 $\mu \mathrm{l})$ is added to $150 \mu \mathrm{l}$ of serum free RPMI media (200 $\mu \mathrm{l}$ per well) and incubated at $37{ }^{\circ} \mathrm{C}, 5 \% \mathrm{CO}$ for $45 \mathrm{~min}$. Cell viability was measured using the cell viability BioApp 2-color protocol. Ten fields were imaged per well and an average cell viability was calculated, based on the ratio of dead to live cells. Samples were carried out in duplicate and to the $n-3$.

\section{Transmission electron microscopy}

Cells. Samples for transmission electron microscopy (TEM) were first fixed in $2.5 \%$ glutaraldehyde in $0.1 \mathrm{M}$ Sørensen's phosphate buffer for a minimum of $2 \mathrm{~h}$ at room temperature and post fixed in 1\% osmium tetroxide in Sørensen's phosphate buffer for $1 \mathrm{~h}$ at room temperature. Subsequently, the specimens were dehydrated in a graded ethanol series (30\%, 50\%, $70 \%, 90 \%, 100 \%)$. When dehydration was complete, samples were transferred from $100 \%$ ethanol to a mixture of 1 part of ethanol and 1 part of epoxy resin for $1 \mathrm{~h}$. To complete the resin infiltration the samples were placed in $100 \%$ resin at $+37^{\circ} \mathrm{C}$ for $2 \mathrm{~h}$. Finally samples were embedded in resin, placed at $+60{ }^{\circ} \mathrm{C}$ for $24 \mathrm{~h}$ to complete polymerisation. For orientation purposes, $500 \mathrm{~nm}$ sections were cut from each sample at, stained with toluidine blue, and examined by light microscopy (Leica DMLB, Leica Microsystems, Germany). From these survey sections areas of interest were identified and ultrathin $(80 \mathrm{~nm})$ sections were cut using a Leica EM UC6 ultramicrotome (Leica Microsystems, Wetzlar, Germany). These sections were collected on 200 mesh thin bar copper grids, stained with uranyl acetate for $20 \mathrm{~min}$, lead citrate for $5 \mathrm{~min}$ and examined by transmission electron microscopy (Tecnai G2 12 BioTWIN using an accelerating voltage of $120 \mathrm{kV}$ ).

\section{High resolution imaging}

After initial characterisation at lower magnification, multiple ultrathin sections of each sample ( $4 \mathrm{~h}$ and $24 \mathrm{~h}$ exposure) were viewed in an FEI Titan 80-300 scanning/transmission electron microscope (S/TEM) operated at $300 \mathrm{kV}$. Bright-field TEM images were captured with a maximum acquisition time of $0.5 \mathrm{~s}$.

An operating voltage of $300 \mathrm{kV}$ was chosen over $80 \mathrm{kV}$ after a beam damage study showing the increased radiolysis damage caused to the cells at lower operating voltage. In our HRTEM images, no visible damage to the f-MWNTs was observed after 
direct exposure to the beam for the duration of the acquisition. Prolonged exposure ( $>10 \mathrm{~min}$ ) to the beam at $300 \mathrm{kV}$, which is above the threshold for knock-on damage in carbon, was found to lead to a reduction, never an increase, in the graphitic structure of the material.

\section{Western blotting}

The cell lysis was performed as described previously (Verma et al., 2009). The protein content of the cell lysates was determined by Bradford assay. Sodium dodecyl sulphate polyacrylamide gel electrophoresis (SDS-PAGE) of the cell lysates and subsequent western immunoblotting were performed as described previously (Verma et al., 2009). The immunoreactive bands were visualized using the chemiluminescence detection system (Cell signalling Technology, Danvers, MA) and subsequently documented on Kodak light sensitive film (Cedex, France).

\section{Raman spectroscopy}

Graphene/carbon nanotubes: both suspensions were prepared at a concentration of $0.029 \mathrm{mg} \mathrm{ml}^{-1}, 20 \mu \mathrm{l}$ of this suspension was pipetted onto silicon and allowed to dry. Raman spectra were acquired using a $100 \times$ objective, 532 nm, Horiba Jobin Yvon LabRAM HR system.

Cells. In preparation for spectral acquisition the primary macrophages were fixed with $4 \%$ paraformaldehyde for $30 \mathrm{~min}$ at room temperature, washed once with PBS and dehydrated in ascending grades of ethanol (60\% for $20 \mathrm{~min}$, $80 \%$ for $20 \mathrm{~min}$, $90 \%$ for $20 \mathrm{~min}$ and finally $100 \%$ for $30 \mathrm{~min}$ ). Raman spectroscopic mapping was carried out using a Witec Alpha 300 upright Raman spectrometer (WITec, Germany) with a $20 \times$ dry objective lens, $532 \mathrm{~nm}$ excitation at a low power $(\sim 200 \mu \mathrm{W})$. For each scan three spectra were taken per $\mu \mathrm{m}$ in both $x$ and $y$ directions. Brightfield images of each scanned area were recorded. Following spectral acquisition, data analysis was carried out using the WITec analysis software.

\section{Thermogravimetric analysis}

In preparation for thermogravimetric analysis (TGA), primary macrophages were seeded at a density of $5 \times 10^{6}$ cells per $\mathrm{ml}$ in 6-well plates. Following treatment (untreated, graphene or SWCNT treated), the cells from three plates were scraped and pooled together for each TGA sample. The samples were spun for $180 \mathrm{~min}$ at $15000 \mathrm{rpm}$.

\section{X-ray photoelectron spectroscopy}

X-ray photoelectron spectroscopy (XPS) was performed using a system equipped with a VG CLAM II electron analyzer and PSP twin anode source. $\mathrm{Mg} \mathrm{KR}(h \nu) 1253.6 \mathrm{eV}$ spectra were recorded at $10 \mathrm{eV}$ pass energy and $2 \mathrm{~mm}$ slits, yielding an overall energy resolution of $0.85 \mathrm{eV}$. Samples were introduced via a loadlock, and measurement base pressure was better than 10-9 mbar. The C 1s core-level spectra were deconvoluted into several components which originate from different chemical environments of the carbon, using the Doniach-Sunjic line shape (with an asymmetry index of 0.07$)$ for the graphitic $\left(\mathrm{sp}^{2}\right)$ carbon component and the standard Gaussian-Lorentzian line shape for the other components.

\section{Discussion}

In the present study, the in vitro response of human primary macrophages following exposure to pristine (pSWCNT) and pristine graphene (PG) is explored. PG was phagocytosed readily by the macrophages and transported into single membrane lysosomal vesicles. PG did not induce an autophagic response and was not degraded following $24 \mathrm{~h}$ accumulation within the cells. In contrast, the pSWCNT were not readily phagocytosed by the macrophages. Nevertheless, they induced an autophagic response, which emphasises the fact that whether the nanomaterial is internalised or not, it can still have an indirect impact on the biological organisation. The literature predominantly reports on the bio-interaction of the graphene and carbon nanotube family of nanomaterials with very different edge effects and surface chemistries, all of which contribute to the cellular response but are not intrinsic to pristine graphene or pristine single walled carbon nanotubes. ${ }^{21-31}$ They have very different edge effects and surface chemistries, all of which contribute to the cellular responses, but are not intrinsic to the pristine nanomaterial. Importantly, in this study, the response of the primary macrophages to PG and pSWCNT is compared and contrasted. This enables the direct comparison of two different carbonaceous nanomaterials with similar surface chemistries but different geometries. Such studies are rare, making the overall comparative safety considerations of these two nanomaterials difficult.

The live-dead assay, real time impedance results and confocal microscopic analysis revealed that there were no signs of acute toxicity due to the PG or pSWCNT following the exposure to the concentrations up to $10 \mu \mathrm{g} \mathrm{ml} \mathrm{m}^{-1}$. Electron microscopy demonstrated that PG was phagocytosed in abundance by the cells, and transported into single membrane lysosomal vesicles. In contrast, there was no evidence of phagocytosis of the pSWCNT, no large single membrane lysosomal vesicles detected rather an increase in the presence of double membrane vesicles was observed. Raman mapping of the PG within the PM confirmed that PG was taken up by the cells in abundance and was located in discrete vesicular regions throughout the entire cell, which is consistent with the observations made by confocal microscopy and TEM, whereas the pSWCNT were not taken up by the cells to the same extent. Quantification of this uptake was carried out using TGA analysis and revealed $20-30 \%$ of the remaining dry mass was made up of PG. The integrity of the PG accumulated within the cells was analysed using HRTEM which revealed that even after $24 \mathrm{~h}$ of accumulation within the lysosomal vesicles, graphene remained graphitic showing no signs of biodegradation. This is not surprising as recent studies revealed short carboxylated SWCNT were indeed degraded by myeloperoxidase in neutrophils and to a lesser extent in macrophages. ${ }^{32,33}$ This suggests that some kind of a structural defect or carboxyl site is required 
to trigger the biodegradation process of the carbon nanotubes which could also be applicable to graphene.

The fact that the SWCNT were not taken up as readily as the PG by the primary human macrophages comes as no surprise. Literature contains numerous reports on the plentiful uptake of SWCNT which have been functionalised. ${ }^{34-36}$ Any account on degradation of CNT within cells has been enabled by some degree of CNT surface modification such cutting or functionalization..$^{32,33,37-39}$ Reports of direct imaging of SWCNT within cells using TEM are scarce as it is difficult to discriminate between the carbon nanotubes and the carbon rich sub-cellular environment. ${ }^{40}$ The focus here is on the subcellular response, as opposed to the uptake mechanism which have been previously documented, a schematic by Zhu et al. demonstrates very well the observations seen here for the uptake of a $\sim 500 \mathrm{~nm}$ nanomaterial. ${ }^{15}$ They highlight the importance of the nanomaterial size and aspect ratio in determining cellular uptake with is a highly regulated process by the cells. Whereas other carbonaceous material such as fullerenes which fall into $\sim 120 \mathrm{~nm}$ size range are taken up by clathrin mediated endocytosis. ${ }^{\mathbf{4 1}}$

Here we present Raman mapping which shows trace amounts of SWCNT within the cells so uptake is not ruled out completely. The most striking subcellular features observed within the primary macrophages following treatment with pSWCNT was the formation of multiple double membrane autophagic vesicles packed with dense region which are not present in the untreated or PG treated cells. Microscopic and biochemical techniques confirmed that pSWCNT induced autophagy and PG did not. These data confirm that two different catabolic pathways are triggered in response to the pSWCNT and PG, two carbonaceous nano-materials with similar surface chemistries but unique geometries, an autophagic and lysosomal response, respectively. Despite the fact that a broad range of nanomaterials have been found to induce autophagy, ${ }^{\mathbf{4 2 - 4 6}}$ it is still difficult to say at this stage what primarily drives this autophagic response. Interestingly, the key difference between the PG and PSWCNT in our study is the shape, as both have similar surface chemistries. Previous reports have shown the autophagic response induced by silver nanowires in macrophages. ${ }^{18}$ Could this imply that the fibrous shape of the pSWCNT and silver wire type nanomaterials is one of the key contributing factors inducing an autophagic response? The hazards of high aspect ratio nanomaterials, where fibre pathogenicity is observed across a multitude of materials, are well studied and understood. ${ }^{4-50}$ It is entirely possible that autophagy serves as an important contributing factor in this process. On the other hand, there are a number of disease conditions where the autophagic process is disrupted such as Parkinson's, Huntington's and Alzheimer's disease ${ }^{51}$ and the ability to mimic the properties that drive such an autophagic response would be desirable. Perhaps a biodegradable nanomaterial that mimics the properties of the pSWCNT, which induce this autophagic response, could be developed. All evidence points to the nanomaterial shape as one of the key factors driving this autophagic response.

\section{Conclusions}

Here, for the first time the catabolic processes induced in primary human macrophages by two different pristine carbonaceous nanomaterials with similar surface chemistries but different geometries are compared and contrasted. PG does not behave like any of its derivatives, it is phagocytosed by primary macrophages in abundance, does not induce autophagy and is not degraded following $24 \mathrm{~h}$ accumulation within these cells. In contrast, the pSWCNT are not phagocytosed by the primary macrophages yet induce an autophagic response. This emphasises the importance of taking a comparative multimodal approach in assessing the biocompatibility of various nanomaterials. This study reveals that PG and pSWCNT differ significantly in their cellular interactions and subsequently induced catabolic, lysosomal and autophagic responses respectively. The dramatic influence of physico-chemical properties of nanomaterials on their subsequent impact at the cellular and sub-cellular levels is verified here.

\section{Acknowledgements}

The authors would like to acknowledge SFI funded CRANN-HP collaboration (Contracts No. 08/CE/I1432S) for financial support. This work was also supported in part by EC FP7 NMP Project NAMDIATREAM (ref. 246479), the Higher Educational Authority of Ireland (HEA) and AMBER. We thank Tiina O'Neill (Electron Microscopy Core Facility, UCD Conway Institute, UCD, Belfield, Dublin 4) for staining and EM imaging.

\section{Notes and references}

1 OECD, Organisation for Economic Co-operation and Development, 2012, ENV/JM/MONO(2012)40.

2 K. A. Clark, R. H. White and E. K. Silbergeld, Regul. Toxicol. Pharmacol., 2011, 59, 361-363.

3 A. G. Oomen, P. M. J. Bos, T. F. Fernandes, K. Hund-Rinke, D. Boraschi, H. J. Byrne, K. Aschberger, S. Gottardo, F. von der Kammer, D. Kühnel, D. Hristozov, A. Marcomini, L. Migliore, J. Scott-Fordsmand, P. Wick and R. Landsiedel, Nanotoxicology, 2013, 8, 334-348.

4 T. Puzyn, D. Leszczynska and J. Leszczynski, Small, 2009, 5, 2494-2509.

5 S. D. Bergin, V. Nicolosi, P. V. Streich, S. Giordani, Z. Sun, A. H. Windle, P. Ryan, N. P. P. Niraj, Z.-T. T. Wang, L. Carpenter, W. J. Blau, J. J. Boland, J. P. Hamilton and J. N. Coleman, Adv. Mater., 2008, 20, 1876-1881.

6 M. S. Dresselhaus, G. Dresselhaus, A. Jorio, A. G. Souza Filho and R. Saito, Carbon, 2002, 40, 2043-2061.

7 V. Nicolosi, M. Chhowalla, M. G. Kanatzidis, M. S. Strano and J. N. Coleman, Science, 2013, 340, 1226419.

8 K. R. Paton, E. Varrla, C. Backes, R. J. Smith, U. Khan, A. O'Neill, C. Boland, M. Lotya, O. M. Istrate, P. King, T. Higgins, S. Barwich, P. May, P. Puczkarski, I. Ahmed, M. Moebius, H. Pettersson, E. Long, J. Coelho, S. E. O'Brien, E. K. McGuire, B. M. Sanchez, G. S. Duesberg, N. McEvoy, T. J. Pennycook, C. Downing, 
A. Crossley, V. Nicolosi and J. N. Coleman, Nat. Mater., 2014, 3, 624-630.

9 C. Casiraghi, A. Hartschuh, H. Qian, S. Piscanec, C. Georgi, A. Fasoli, K. S. Novoselov, D. M. Basko and A. C. Ferrari, Nano Lett., 2009, 9, 1433-1441.

10 U. Khan, A. O'Neill, M. Lotya, S. De and J. N. Coleman, Small, 2010, 6, 864-871.

11 M. Lotya, P. J. King, U. Khan, S. De and J. N. Coleman, ACS Nano, 2010, 4, 3155-3162.

12 R. J. Smith, P. J. King, C. Wirtz, G. S. Duesberg and J. N. Coleman, Chem. Phys. Lett., 2012, 531, 169-172.

13 A. C. Ferrari, J. C. Meyer, V. Scardaci, C. Casiraghi, M. Lazzeri, F. Mauri, S. Piscanec, D. Jiang, K. S. Novoselov, S. Roth and A. K. Geim, Phys. Rev. Lett., 2006, 97, 187401.

14 Y. Hernandez, V. Nicolosi, M. Lotya, F. M. Blighe, Z. Sun, S. De, I. T. McGovern, B. Holland, M. Byrne, Y. K. Gun'Ko, J. J. Boland, P. Niraj, G. Duesberg, S. Krishnamurthy, R. Goodhue, J. Hutchison, V. Scardaci, A. C. Ferrari and J. N. Coleman, Nat. Nanotechnol., 2008, 3, 563-568.

15 M. Zhu, G. Nie, H. Meng, T. Xia, A. Nel and Y. Zhao, Acc. Chem. Res., 2013, 46, 622-631.

16 I. Tanida, T. Ueno and E. Kominami, Int. J. Biochem. Cell Biol., 2004, 36, 2503-2518.

17 Y. H. Yoon, K. S. Cho, J. J. Hwang, S.-J. Lee, J. A. Choi and J.-Y. Koh, Invest. Ophthalmol. Visual Sci., 2010, 51, 60306037.

18 J. Conroy, N. K. Verma, P. E. Lyons, J. Coleman, M. P. O'Sullivan, H. Kornfeld, D. Kelleher and Y. Volkov, Toxicol. Appl. Pharmacol., 2012, 264, 451-461.

19 N. K. Verma, K. Crosbie-Staunton, A. Satti, S. Gallagher, K. B. Ryan, T. Doody, C. McAtamney, R. MacLoughlin, P. Galvin, C. S. Burke, Y. Volkov and Y. K. Gun'ko, J. Nanobiotechnol., 2013, 11, 1-12.

20 N. K. Verma, E. Moore, W. Blau, Y. Volkov and P. Ramesh Babu, J. Nanopart. Res., 2012, 14, 1-11.

21 Y. Chang, S.-T. Yang, J.-H. Liu, E. Dong, Y. Wang, A. Cao, Y. Liu and H. Wang, Toxicol. Lett., 2011, 200, 201-210.

22 G. Y. Chen, H. J. Yang, C. H. Lu, Y. C. Chao, S. M. Hwang, C. L. Chen, K. W. Lo, L. Y. Sung, W. Y. Luo, H. Y. Tuan and Y. C. Hu, Biomaterials, 2012, 33, 6559-6569.

23 G.-Y. Chen, C.-L. Chen, H.-Y. Tuan, P.-X. Yuan, K.-C. Li, H.-J. Yang and Y.-C. Hu, Adv. Healthcare Mater., 2014, 3, 1486-1495.

24 G.-Y. Chen, H.-J. Yang, C.-H. Lu, Y.-C. Chao, S.-M. Hwang, C.-L. Chen, K.-W. Lo, L.-Y. Sung, W.-Y. Luo, H.-Y. Tuan and Y.-C. Hu, Biomaterials, 2012, 33, 6559-6569.

25 E. L. K. Chng and M. Pumera, RSC Adv., 2015, 5, 3074-3080. 26 S. M. Chowdhury, G. Lalwani, K. V. Zhang, J. Y. Yang, K. Neville and B. Sitharaman, Biomaterials, 2013, 34, 283293.

27 S. Das, S. Singh, V. Singh, D. Joung, J. M. Dowding, D. Reid, J. Anderson, L. Zhai, S. I. Khondaker, W. T. Self and S. Seal, Part. Part. Syst. Charact., 2013, 30, 148-157.

28 D. Elgrabli, W. Dachraoui, C. Ménard-Moyon, X. J. Liu, D. Bégin, S. Bégin-Colin, A. Bianco, F. Gazeau and D. Alloyeau, ACS Nano, 2015, 9(10), 10113-10124.
29 M. Orecchioni, D. Bedognetti, F. Sgarrella, F. Marincola, A. Bianco and L. Delogu, J. Transl. Med., 2014, 12, 138.

30 A. Sasidharan, L. S. Panchakarla, P. Chandran, D. Menon, S. Nair, C. N. R. Rao and M. Koyakutty, Nanoscale, 2011, 3, 2461-2464.

31 S. K. Singh, M. K. Singh, P. P. Kulkarni, V. K. Sonkar, J. J. A. Grácio and D. Dash, ACS Nano, 2012, 6, 2731-2740.

32 V. E. Kagan, N. V. Konduru, W. Feng, B. L. Allen, J. Conroy, Y. Volkov, I. I. Vlasova, N. A. Belikova, N. Yanamala, A. Kapralov, Y. Y. Tyurina, J. Shi, E. R. Kisin, A. R. Murray, J. Franks, D. Stolz, P. Gou, J. Klein-Seetharaman, B. Fadeel, A. Star and A. A. Shvedova, Nat. Nanotechnol., 2010, 5, 354359.

33 A. A. Shvedova, A. A. Kapralov, W. H. Feng, E. R. Kisin, A. R. Murray, R. R. Mercer, C. M. S. Croix, M. A. Lang, S. C. Watkins, N. V. Konduru, B. L. Allen, J. Conroy, G. P. Kotchey, B. M. Mohamed, A. D. Meade, Y. Volkov, A. Star, B. Fadeel and V. E. Kagan, PLoS One, 2012, 7, e30923. 34 K. Kostarelos, L. Lacerda, G. Pastorin, W. Wu, W. Sebastien, J. Luangsivilay, S. Godefroy, D. Pantarotto, J.-P. Briand, S. Muller, M. Prato and A. Bianco, Nat. Nanotechnol., 2007, 2, 108-113.

35 B. R. Smith, B. GhosnEliver Eid, H. Rallapalli, J. A. Prescher, T. Larson, L. A. Herzenberg and S. S. Gambhir, Nat. Nanotechnol., 2014, 9, 481-487.

36 J. T.-W. Wang and K. T. Al-Jamal, Nanomedicine, 2015, 10, 2639-2642.

37 A. Nunes, C. Bussy, L. Gherardini, M. Meneghetti, M. A. Herrero, A. Bianco, M. Prato, T. Pizzorusso, K. T. AlJamal and K. Kostarelos, Nanomedicine, 2012, 7, 1485-1494. 38 Y. Zhao, B. L. Allen and A. Star, J. Phys. Chem. A, 2011, 115, 9536-9544.

39 V. E. Kagan, A. A. Kapralov, C. M. S. Croix, S. C. Watkins, E. R. Kisin, G. P. Kotchey, K. Balasubramanian, I. I. Vlasova, J. Yu, K. Kim, W. Seo, R. K. Mallampalli, A. Star and A. A. Shvedova, ACS Nano, 2014, 8(6), 5610-5621. 40 A. E. Porter, M. Gass, K. Muller, J. N. Skepper, P. A. Midgley and M. Welland, Nat. Nanotechnol., 2007, 2, 713-717.

41 L. Wei, C. Chunying, Y. Chang, W. Taotao, Z. Yuliang, L. Fang, C. Zhen, M. Huan, G. Yuxi, Y. Hui, X. Genmei, Z. Feng, C. Zhifang, Z. Xujia, Y. Fuyu, H. Dong, T. Xianhua and Z. Yingge, Nanotechnology, 2008, 19, 145102.

42 M. I. Khan, A. Mohammad, G. Patil, S. A. H. Naqvi, L. K. S. Chauhan and I. Ahmad, Biomaterials, 2012, 33, 1477-1488.

43 X. Ma, Y. Wu, S. Jin, Y. Tian, X. Zhang, Y. Zhao, L. Yu and X.-J. Liang, ACS Nano, 2011, 5, 8629-8639.

44 E.-J. Park, N. E. M. Zahari, E.-W. Lee, J. Song, J.-H. Lee, M.-H. Cho and J.-H. Kim, Toxicol. in Vitro, 2014, 28, 442-450.

45 S. T. Stern, B. S. Zolnik, C. B. McLeland, J. Clogston, J. Zheng and S. E. McNeil, Toxicol. Sci., 2008, 106, 140-152.

46 B. Wan, Z.-X. Wang, Q.-Y. Lv, P.-X. Dong, L.-X. Zhao, Y. Yang and L.-H. Guo, Toxicol. Lett., 2013, 221, 118-127.

47 K. Donaldson, F. Murphy, A. Schinwald, R. Duffin and C. A. Poland, Nanomedicine, 2010, 6, 143-156.

48 G. Oberdorster, E. Oberdorster and J. Oberdorster, Environ. Health Perspect., 2005, 113, 823-839. 
49 C. A. Poland, R. Duffin, I. Kinloch, A. Maynard, W. A. H. Wallace, A. Seaton, V. Stone, S. Brown, W. MacNee and K. Donaldson, Nat. Nanotechnol., 2008, 3, 423-428.

50 A. A. Shvedova, E. Kisin, A. R. Murray, V. J. Johnson, O. Gorelik, S. Arepalli, A. F. Hubbs, R. R. Mercer,
P. Keohavong, N. Sussman, J. Jin, J. Yin, S. Stone, B. T. Chen, G. Deye, A. Maynard, V. Castranova, P. A. Baron and V. E. Kagan, Am. J. Physiol.: Lung Cell. Mol. Physiol., 2008, 295, L552-L565.

51 W. Bursch and A. Ellinger, Folia Neuropathol., 2005, 43, 297310. 